\title{
Fuel Fire Test Results for RX-08-FK in a Toroidal Composite Vessel
}

Wardell Black

Don Bretl

Erica von Holtz

John Didlake

Mike Ferrario

Jay Spingarn

Jill Schwegel

July 1993

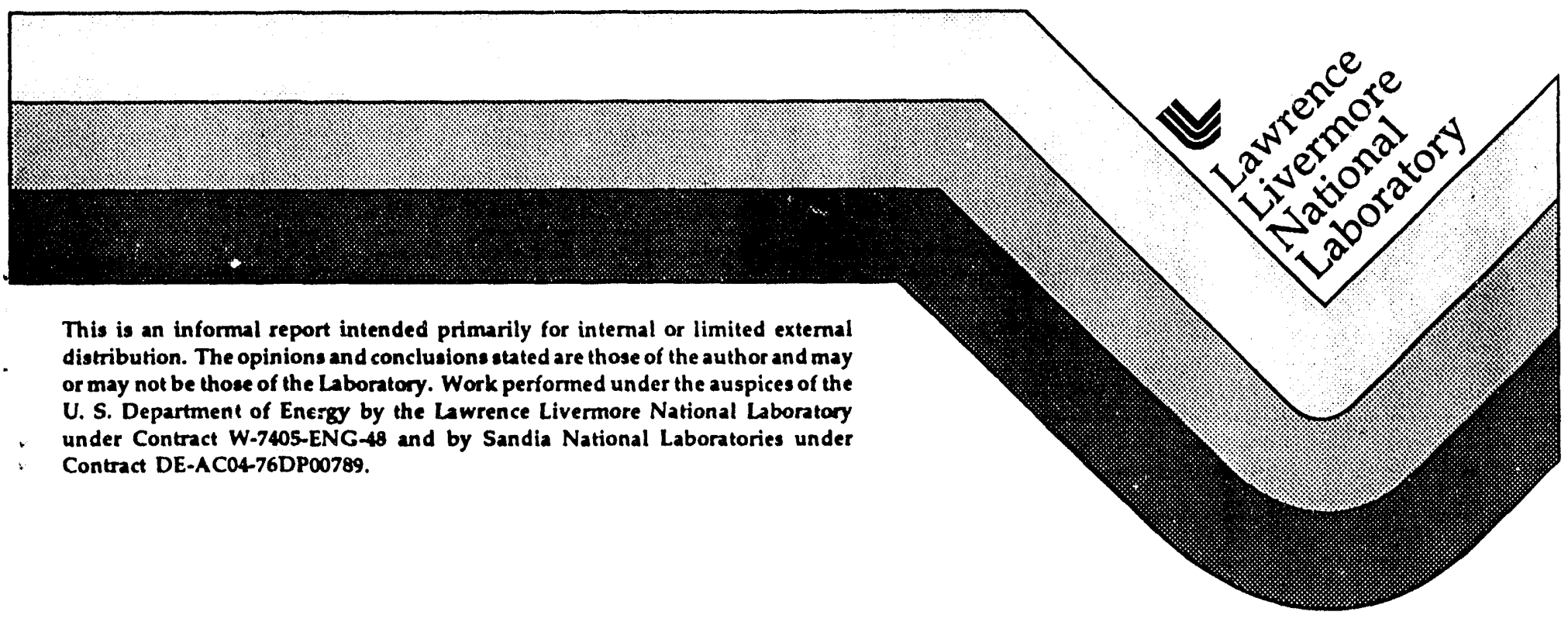




\section{DISCLAIMER}

This document was prepared as an account of work sponsored by an agency of the United States Government. Neither the United States Government nor the University of California nor any of their employees, makes any warranty, express or implied, or assumes any legal liability or responsibility for the accuracy, completeness, or usefulness of any information, apparatus, product, or process disclosed, or represents that its use would not infringe privately owned rights. Reference herein to any specific commercial products, process, or service by trade name, trademark, manufacturer, or otherwise, does not necessarily constitute or imply its endorsement, recommendation, or favoring by the United States Government or the University of California. The views and opinions of authors expressed herein do not necessarily state or reflect those of the United States Government or the University of California, and shall not be used for advertising or product endorsement purposes.

This report has been reproduced" directly from the best available copy.

Available to DOE and DOE contractors from the Office of Scientific and Technical Information

P.t Box 62, Oak Ridge, TN 37831

Prices available from (615) 576-8401, FTS 626-8401

A vailable to the public from the

National Technical Information Service

US. Department of Commerce

5285 Port Royal Rd.,

Springfield, VA 22161 


\title{
Fuel Fire Test Results for RX-08-FK in a Toroidal Composite Vessel
}

\author{
Wardell Black, Don Bretl, and Erica von Holtz \\ Lawrence Livermore National Laboratory \\ P. O. Box 808 \\ Livermore, CA 94551 \\ John Didlake, Mike Ferrario, Jay Spingarn, and Jill Schwegel \\ Sandia National Laboratories \\ P. O. Box 969 \\ Livermore, CA 94551-0969
}

\begin{abstract}
A fuel fire test was conducted on October 15, 1992, during which a toroidal composite vessel containing $6.5 \mathrm{~kg}$ of RX-08-FK Paste Extrudable Explosive was subjected to a dynamic (transient) thermal environment. The vessel was mounted inside a closed, but vented, thin-walled steel cylinder, and the entire assembly was then engulfed in a fuel fire. Approximately 5 minutes into the test the PEX began to burn. At the time the reaction of the PEX occurred, the temperatures of the inside wall of the steel cylinder were $815^{\circ} \mathrm{C}\left(1500^{\circ} \mathrm{F}\right)$ and the temperatures on the outside wall of the composite vessel ranged from 163 $454^{\circ} \mathrm{C}\left(325-850^{\circ} \mathrm{F}\right)$. Subsequently, temperatures in excess of $95^{\circ}{ }^{\circ} \mathrm{C}$ were reached inside the cylinder for tens of minutes. Based on the criteria set forth in MILSTD-1648A(AS), the RX-08-FK-loaded vessel passed the fuel fire test, because no violent reaction beyond burning was observed.

\section{Introduction}

In 1990, Lawrence Livermore National Laboratory (LLNL) and Sandia National Laboratories (SNL) began to work together on Paste. Extrudable Explosives (PEX) storage and transfer systems for the SNL. Focal Point Frogram. Two slow cook-off tests have previously been done with toroidal comprosite vessels using RX-08-FK. 1,2 Those tests were designed a = a art of the development of the PEX Main Charge transfer system a jovidi ? information at both the system level and the produc ve!. At the product level, we gained additional information about the in saction the selected composite storage vessel materials and the reaction si PF in a slow heat environment. A relatively high order detonation icacicon in either test would have resulted in a re-design of the storage vessel and! $\mathrm{r}$ ehing, in the materials of construction for the vessel. Those tests al $c$; some more information on the pressure/temperature environment $\therefore$. st the stronglink valve must survive. (The stronglink is the component wich would prevent premature transfer of the PEX in a weapons system.) At the system level, we gained information which gives us a better indication of the probability of
\end{abstract}


scattering special nuclear material in abnormal thermal environments, as well as providing some indication of personnel hazards in that type of environment.

\section{Test Objectives}

The main objectives of this test are to determine the temperature of reaction, the magnitude of reaction and the structural response of a PEX (RX-08FK) loaded composite storage vessel under dynamic (transient) heating and compare them with the results of the two slow cook-off tests. ${ }^{3}$ A secondary objective is to determine the feasibility for using optical instrumentation with explosive components in high thermal environments. This test differs from the slow cook-off tests in that it subjects the PEX-filled vessel to an intense fire environment for a period of 30 minutes. The reactions are not expected to be as severe for this type of test.

The fast cook-off test, as defined by MIL-STD-1648A(AS), ${ }^{4}$ is used to assess the reaction of a munition containing energetic materials when exposed to a fuel fire while aboard a ship by engulfing the test item for at least 15 minutes in a fuel fire and recording its reaction as a function of time. The intent is that the fire represents a deck fire under a munition while on the wing of its aircraft. The MIL-STD applies to all munitions used aboard air capable ships. The reaction of the munition is evaluated within six categories which are defined in the standard in order of increasing severity as follows: burning, deflagration, explosion, propulsion, partial detonation, and detonation. The definitions of these six categories are given in the Appendix. Determination of the risk to shipboard fire fighting personnel and to the ship, not nuclear safety, is the major focus of the MIL-STD testing and documentation. We deviated from MIL-STD-1648A(AS) with respect to one requirement. The standard calls for this test to be conducted on two separate vessels in two separate fires; we did not repeat this test, nor do we have any plans to do so.

\section{Materials Tested}

The PEX used in this test was RX-08-FK; the formulation for this material is shown in Table 1. RX-08-FK is an intimate mix of five nominal components. The components are octahydro-1,3,5,7-tetranitro-1,3,5,7-tetrazocine (HMX), formal mixture number 1 (FM-1), ethyl 4,4-dinitropentanoate (EDNP), amorphous silica (Cab-O-Sil ${ }^{\mathrm{TM}} \mathrm{EH}-5$, from the Cabot Corporation, is used), and ethylene glycol. The HMX used is a special grade of material, called LX-04 grade, which has a median particle-size distribution of 55 microns. FM-1 is itself a mixture of three related formals: $50 \% 1$-[(2-fluoro-2,2dinitroethoxy)methoxy]-2,2-dinitropropane (MF-1), and 25\% each of 1,1'[methylenebis(oxy)] bis[2,2-dinitropropane] (BDNPF) and 1,1'[methylenebis(oxy)] bis[2-fluoro-2,2-dinitroethane] (FEFO). (The ingredients in and properties of RX-08-FK are described in detail in Reference 5.)

The toroidal composite vessel was fabricated at Fiber Innovations, Norwood, Massachusetts, and assembled at Sandia. A detailed discussion of the fabrication process is provided in References 1 and 2. As in the second slow 
Table 1. Formulation of RX-08-FK

$\begin{array}{lcc}\text { Ingredient } & \text { Wt. \% } & \text { Vol. \% } \\ \text { HMX } & 72.8 & 67.0 \\ \text { FM-1 } & 14.8 & 17.1 \\ \text { EDNP } & 10.3 & 14.1 \\ \text { Cab-O-Sil TM } & 2.0 & 1.6 \\ \text { Ethylene Glycol } & 0.1 & 0.2\end{array}$

cook-off test, the mock stronglink and fill plug insert were mechanically locked into the PEX vessel using set-screws. ${ }^{2}$ The vessel was then sent to LLNL, where the thermocouples and high temperature strain gauges were installed. Unlike the slow cook-off tests, where the temperature is uniform throughout the test enclosure and the PEX vessel, the fuel fire creates considerably higher temperatures for the instrumentation outside the vessel than for the PEX itself. This creates problems for the wire insulation and solder joints generally used, and special, and unfortunately relatively delicate, attachment schemes were developed. Ultimately the vessel was successfully filled with PEX, while a rough vacuum was maintained on the inside and outside of the vessel. No indications of liner leaks were seen during or after loading.

This third vessel included free volume for PEX expansion and a massmock for the stronglink, features also incorporated into the first two test vessels. ${ }^{1,2}$ The free volume included in the PEX vessel was again chosen to be equal to the expansion of the PEX from the fill temperature (ambient) to $80^{\circ} \mathrm{C}$, which equates to approximately $2 \%$ free volume. This worked well in the first test, as was evidenced by the strain gauge data, which did not show any appreciable rise in pressure in the vessel until the test temperatures were above $77^{\circ} \mathrm{C}$. We also included the mass-mock stronglink valve, since it is a baseline component in the WR design. We were still concerned that this concentration of metal might provide a mechanism for an early or accelerated response from the PEX. The mass-mock valve was again located at the vacuum port.

Figure 1 shows the vessel in the post-fill condition. (For details of the prefill condition, see Reference 2.) As in the two previous tests, a vacuum valve (Figure 1, item 7) was installed at one end to evacuate the expansion space prior to testing.

\section{Test Description}

The procedures for the fuel fire test are defined in MIL-STD-1648A(AS). ${ }^{4}$ The test set-up was as follows. The PEX vessel was placed within a thin walled steel tube (see Figure 2), with the axis oriented horizontally $0.9 \mathrm{~m}$ above a $3 \mathrm{~m}$ diameter steel pan containing JP-5 fuel $^{6}$ (see Figure 3). The vessel was mounted with the end fittings pointed upward, away from the pool. The $15.2 \mathrm{~cm}$ deep fuel layer $(1140 \mathrm{~L})$, floating on water, was ignited using $225 \mathrm{~g}$ of black powder mixed with $4.5 \mathrm{~kg}$ of smokeless propellant ignited with an electric match. The MIL-STD requires that the flame temperature reach $1000^{\circ} \mathrm{F}\left(538^{\circ} \mathrm{C}\right)$ within 30 
seconds after ignition. (Should it take longer to reach that temperature, the additional time over 30 seconds will be subtracted from the time of reaction.) The average flame temperature for the entire test must be at least $871^{\circ} \mathrm{C}$ $\left(1600^{\circ} \mathrm{F}\right)$, without the contribution of the burning test item, to be considered valid. The average flame temperature is determined by averaging the temperature from the time that the flame reaches $538^{\circ} \mathrm{C}\left(1000^{\circ} \mathrm{F}\right)$ until either all test item reactions are completed or until 15 minutes has elapsed. (The actual time before a PEX reaction occurs was estimated to be 5 minutes.) The test unit was supported on a stainless steel grating and held in place by stainless steel wire wrapped around its ends. The space between the PEX container bulkhead and the end bulkhead was filled with thermal insulation to protect the PEX container instrumentation. A small amount of insulation was placed between the bottom of the PEX vessel and the steel cylinder to preclude direct contact.

Eight thermocouples, eight strain gauges, and nine fiber optic sensors were mounted on or near $:$ carbon fiber composite explosive container. Of these, four thermocouples a... d all of the strain gauges were mounted to the exterior wail of the vessel; this instrumentation wire was routed through the camera end of the metal cylinder. The remaining thermocouples and fiber optic temperature sensors were attached near the vessel with wire or glass tape and the wiring routed out the opposite end of the cylinder. The location of the instrumentation is shown on Figure 4. All cables from the diagnostics attached to the vessel were routed out the end bulkhead nearest to the vessel through a nitrogen cooled hose.

Six thermocouples were located on two vertical supports attached to the grating to monitor the fire temperature a few centimeters from the test unit, four of which were required to demonstrate compliance with the MIL-STD specifications. The progress of the test from the exterior was recorded by two color TV cameras, equipped with sound, located at a distance of $30.5 \mathrm{~m}$ from the set-up at two locations $90^{\circ}$ apart. These views document the extent to which the fire engulfed the assembly and demonstrate the severity (or absence) of the munitions reaction.

Inside the steel cylinder, eight thermocouples were attached to the metal case in two locations at $0^{\circ}, 90^{\circ}, 180^{\circ}$, and $270^{\circ}$ positions, and routed out the camera end through an insulated flexible duct (at the other end from the vessel instrumentation routing). Two additional thermocouples were mounted on a black and white video camera to monitor its temperature. The black and white camera was mounted on an end bulkhead with nitrogen cooling discharging through an insulated metal shroud opening into the interior of the steel container. Unlike the previous two slow cook-off tests, where oven-capable lights were used, only ambient lighting from the heating of the vessel was used in the filming.

All diagnostic cables, which were run through the two insulated flexible ducts, were cooled by a flow of nitrogen gas during the test. The ducts were kept cool with recirculating water. A decision was made to use nitrogen gas cooling rather than compressed air, to simulate the expected oxygen-starved environment inside a weapon container. Two independent gas supplies and 
manifolds were provided - one for each duct. The cooling flow was discharged at a rate estimated to be $560 \mathrm{~L} / \mathrm{min}$. $\left(20 \mathrm{ft}^{3} / \mathrm{min}\right.$.), based on testing at SNL, New Mexico, into the steel cylinder and exhausted through a $5 \mathrm{~cm}$ diameter pipe stub opening on the top surface. It was hoped that the nitrogen flow would expel incidental smoke and maintain the internal camera image as long as possible. The most non-conservative effect of the nitrogen flow was to lower the inside temperature by about $100^{\circ} \mathrm{F}$ (calculated) at peak temperature. This could lead to a small time delay associated with any explosive event. However, since the reaction temperature is much less than the peak temperature, any time delay is expected to be small. The nitrogen purge was initiated about 5 minutes prior to ignition, and was expected to last $45-60$ minutes. A view of the overall test set-up is shown in Figure 5.

\section{Results}

The test was conducted at the Non-violent Explosive Destruct System (NEDS) burn site at Tonopah Test Range (TTR). [TTR is a remote testing facility located near Tonopah, Nevada which is operated by Sandia for the Department of Energy.] The fire began at approximately 7:00 am, October 15, 1992 , and burned out around 7:35 am the same day. The wind speed at the start of the test was less than $5 \mathrm{mph}$. Nonetheless, an examination of the temperatures at the two towers (Figures 6a and $6 \mathrm{~b}$ ) clearly indicates that the flame was pushed to one side. The flame temperature, as measured at the South Tower, reached $538^{\circ} \mathrm{C}\left(1000^{\circ} \mathrm{F}\right)$ in under 25 seconds, satisfying the requirements of the MIL-STD. Similarly, the average flame temperature over the first 15 minutes, including both towers, was about $913^{\circ} \mathrm{C}\left(1675^{\circ} \mathrm{F}\right)$, again satisfying the MIL-STD requirements.

Visual observation during the test indicated that the test assembly remained intact. It was noted that late in the test (10 minutes) a bright flare could be seen exiting from the vent.

Reentry was made to the test area to examine the post-test debris 2 hours later. ${ }^{7}$ The post-test configuration is shown in Figure 7. The video tape from the internal camera was viewed at the close-in instrumentation bunker upon arrival. The internal camera survived for approximately 6 minutes into the fire test, which was longer than expected. From the video, it appeared that a small section of the composite vessel wall blew out and initiated burning on the exterior surface of the composite vessel adjacent to the mock stronglink. This occurred about 5 minutes after initiation of pool fire. The initial burn obscured the picture, making detailed observation impossible. However, after approximately 90 seconds, another reaction occurred with increased flames resulting in the demise of the camera about 15 seconds later.

The steel cylinder was intact after the test and had a layer of black flaky material over most of its exterior, a result of the JP-5 fire. The end plate, nearest the PEX vessel and opposite to the camera, was still attached by the four $0.25^{\prime \prime} \times 20$ UNC bolts that were easily unthreaded. Removal of the end plate revealed that the PEX mounting plate was loose, the two $0.25^{\prime \prime} \times 20$ UNC threaded rods having broken. The mounting plate had fallen away from the 
camera and toward the end plate. The straps on the mounting plate were deformed, allowing the PEX vessel to fall in the opposite direction, i.e., toward the camera. The hole in the end plate where instrumentation cables entered the cabling duct was filled with black fibers thought to be the remains of the fiberglass tape used to bundle the instrumentation cables.

The remains of the graphite-epoxy PEX vessel were removed and examined. The PEX vessel was recognizable and retained its basic shape. Both end plugs, the fill port, and the mass mock stronglink were still in the vessel but were projected out of the vessel $1.27 \mathrm{~cm}$. The aluminum end fittings were entirely melted and resolidified inside the carbonized vessel. They were covered with ash, making them white in appearance. The 'e was also evidence of white ash on the black fibers of the vessel. A small plug on the end of the fitting on the mass mock stronglink was missing. There was a large hole, $10 \mathrm{~cm}$ by $5 \mathrm{~cm}$, on the outer surface of the vessel near the mass mock stronglink. A smaller $4 \mathrm{~cm}$ diameter hole in the vessel wall was found on the opposite end near the fill port. This smaller hole was also on the outer surface, however, it was rotated about $45^{\circ}$ toward the camera. The pieces of the vessel corresponding to these holes were not found. Some melting occurred on the internal end of the steel fill port. The vessel itself was heavily charred and retained its basic shape, but did not retain any significant structural integrity.

\section{Discussion}

Thermocouples were attached to the inside of the steel cylinder in 8 locations surrounding the vessel. These thermocouples gave credible readings for about 8 minutes into the test. During that time, the temperatures appear to have tracked the fire temperatures (measured at the towers) reasonably well. The cylinder reached temperatures around $815^{\circ} \mathrm{C}\left(1500^{\circ} \mathrm{F}\right)$ after 5 minutes. After 8 minutes all of the inside thermocouples became erratic simultaneously. Since the external temperatures remained high, we suspect that the inside probably remained at about $871^{\circ} \mathrm{C}\left(1600^{\circ} \mathrm{F}\right)$ for the remainder of the test.

Thermocouples mechanically attached near the vessel survived about 5 minutes into the test, failing presumably when the PEX began burning. The air temperatures adjacent to the vessel reached between $570-710^{\circ} \mathrm{C}$ during this time. Five thermocouples were bonded directly to the wall of the graphite/epoxy vessel and covered with silicone to provide some insulation from the air temperatures. The temperatures, at 5 minutes, on the exterior of the vessel ranged from $163-454^{\circ} \mathrm{C}\left(325-850^{\circ} \mathrm{F}\right)$. Even with a possible $100^{\circ} \mathrm{C}$ temperature differential between the outside and inside of the vessel, it is clear that the PEX reaction temperature for dynamic heating is greater than that seen during slow cook-off.

The strain gauge wiring was designed to accommodate the expected high air temperatures. Unfortunately, the combination of wire and weld fragility and the need for three wires per gauge reduced gauge survival and only one gauge remained operational throughout the test. That gauge lasted about 5.5 minutes into the test. The data are qualitatively similar to previous runs. No strain is seen during the early stages of vessel heating with gradually increasing 
strain after two minutes. At 5 minutes, the strain reached a maximum of $1250 \mu \varepsilon$ with gauge failure shortly thereafter. The strain drop corresponds with the observed wall failure and initiation of burning.

The fiber optic-based instrumentation also suffered from excessive fragility. The results from this experiment will be discussed in another report. ${ }^{8}$

MIL-STD-1648A(AS) defines the possible outcomes of this test as a burning reaction, deflagration reaction, explosion, propulsion, partial detonation, and detonation. Those definitions are listed, for reference, in the Appendix. The passing criteria for this specific MIL-STD is that no reaction greater than a burning reaction is acceptable during the first 5 minutes in the fire. During the remaining 10 or more minutes of the fire and subsequent cool down, the reaction severity must be no greater than a deflagration reaction. Based on this criteria, the PEX in the toroidal composite vessel has passed the fuel fire test.

\section{Summary}

LLNL and SNL completed a series of cook-off tests on $6.5 \mathrm{~kg}$ of RX-08-FK Paste Extrudable Explosives in a composite toroidal vessel by conducting a fuel fire test at Tonopah Test Range in October of 1992. Our test specimen passed this test based on the criteria set forth in MIL-STD-1648A(AS), since the vessel and test set-up sustained only minor damage from the burning of the explosive which began slightly more than 5 minutes after initiation of the pool fire. The temperatures of the inside wall of the steel cylinder were $815^{\circ} \mathrm{C}\left(1500^{\circ} \mathrm{F}\right)$ and the temperatures on the outside wall of the composite vessel ranged from 163 $454^{\circ} \mathrm{C}\left(325-850^{\circ} \mathrm{F}\right)$ when the PEX began to burn. We had also hoped to determine the feasibility for using optical instrumentation with explosive components in high thermal environments. Unfortunately, because of the fragility of these instruments, no useful data was collected. A detailed report on our experience with the fiber optic-based instrumentation will follow.

The results of this test, coupled with the results seen during the two slow cook-off tests previously conducted, show that reaction of the RX-08-FK was less severe than expected for an HMX-based formulation in all test scenarios. The concept of storing PEX in a composite vessel is very viable, and should be further pursued.

\section{Acknowledgments}

The authors would like to acknowledge the efforts of all personnel involved in this test. Specifically, we would like to thank the following: T. Bennett, SNL (vessel bonding, collar design and assembly); W. Shay and D. Roach, LLNL (thermocouple and strain gauge instrumentation); L. Daniels Jr. and K. Pederson, LLNL (PEX loading); F. Matthews, SNL (test engineering); R. Strait, SNL (data acquisition); Leroy Perea, SNL (event photography); R. Sherwood (TTR Test Director); and D. Smith (TTR explosives technician). 


\section{References}

1. Don Bretl and Erica von Holtz, Lawrence Livermore National Laboratory, John Didlake, Mike Ferrario, and Jay Spingarn, Sandia National Laboratories, Slow Cook-off Test Results for RX-08-FK in a Toroidal Composite Vessel: Test One, UCRL-ID-111990, Lawrence Livermore National Laboratory, Livermore, California, September 1992.

2. Erica von Holtz and Don Bretl, Lawrence Livermore National Laboratory, Jay Spingarn, Mike Ferrario, and John Didlake, Sandia National Laboratories, Slow Cook-off Test Results for RX-08-FK in a Toroidal Composite Vessel: Test Two, UCRL-ID-113360, Lawrence Livermore National Laboratory, Livermore, California, February 1993.

3. John Didlake, "Test Objectives and Planning Report for PEX Main Charge Fuel Fire Test 1," internal document, Sandia National Laboratories, September 24, 1992.

4. Military Standard: Criteria and Test Procedures for Ordnance Exposed to an Aircraft Fuel Fire, MIL-STD-1648A(AS), Department of the Navy, Washington, D.C., September 30, 1982.

5. E. von Holtz, K. Scribner, R. Whipple, and J. Carley, Paste Extrudable Explosives: Their History and Their Status, Proceedings of the 21st Annual Conference of ICT, Page 16-1, July 1990.

6. The most common jet-aircraft fuels are the JP series, which are used by the military as well as by commercial carriers. JP-5 fuel, which is used by the military, is essentially a specially fractionated kerosene which has a higher flash point and lower freezing point than most kerosenes. For more information about this and others in the JP series, refer to Encyclopedia of Explosives and Related Items, by Basil T. Fedoroff and Oliver E. Sheffield, assisted by Seymour M. Kaye and Management Science Associates, PATR 2700 Volume 7, published by Picatinny Arsenal in Dover, New Jersey, 1975, pages J-68 - J-75.

7. John Didlake, "Field Observations of PEX Fuel Fire Test \#1," internal document, Sandia National Laboratories, October, 1992.

8. J. Spingarn, J. Schwegel, and K. Henderson, Sandia National Laboratories, to be published. 


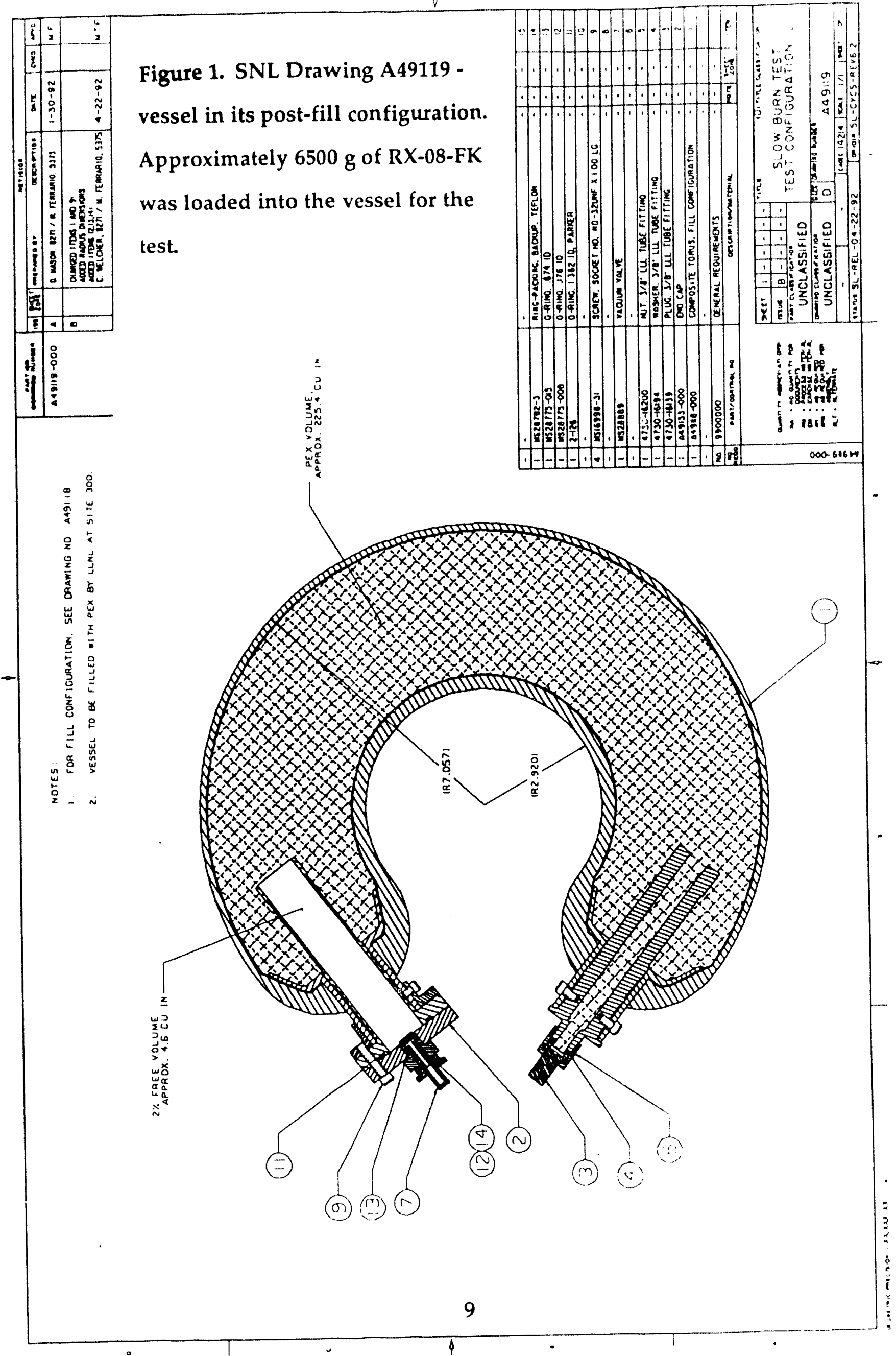




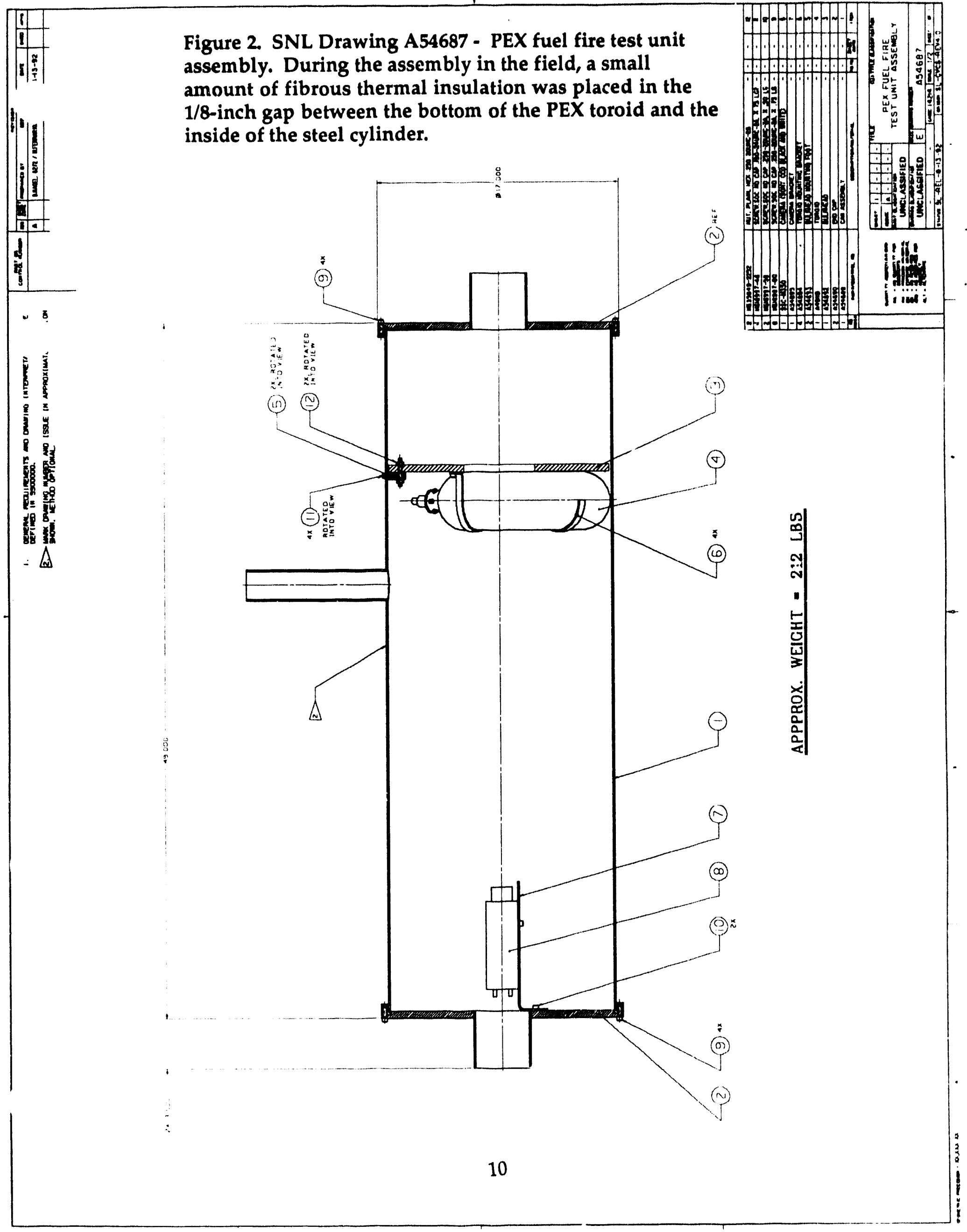




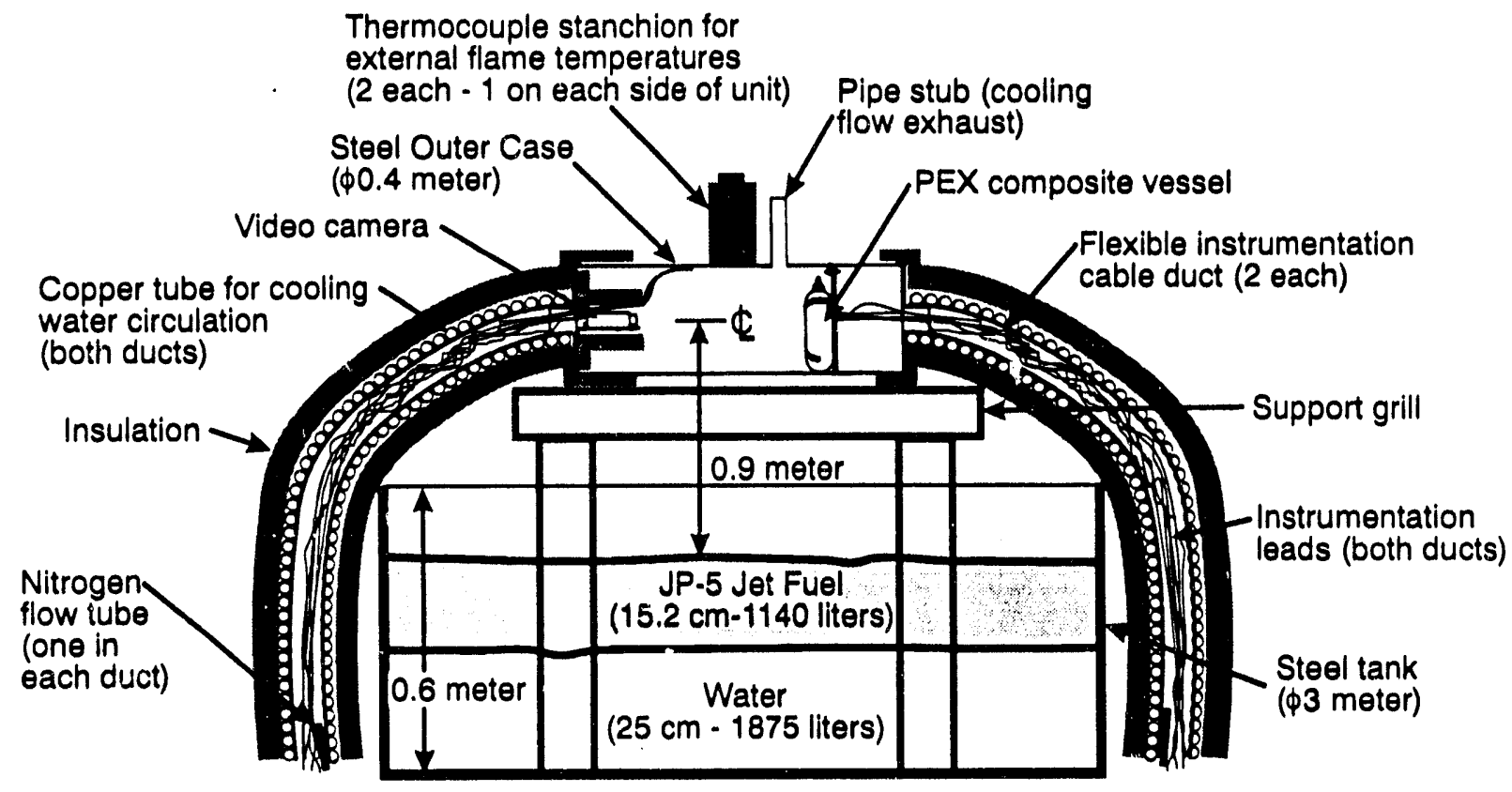

Not to scale

Figure 3. Diagram of the side view of the fuel fire pan, with test assembly. 


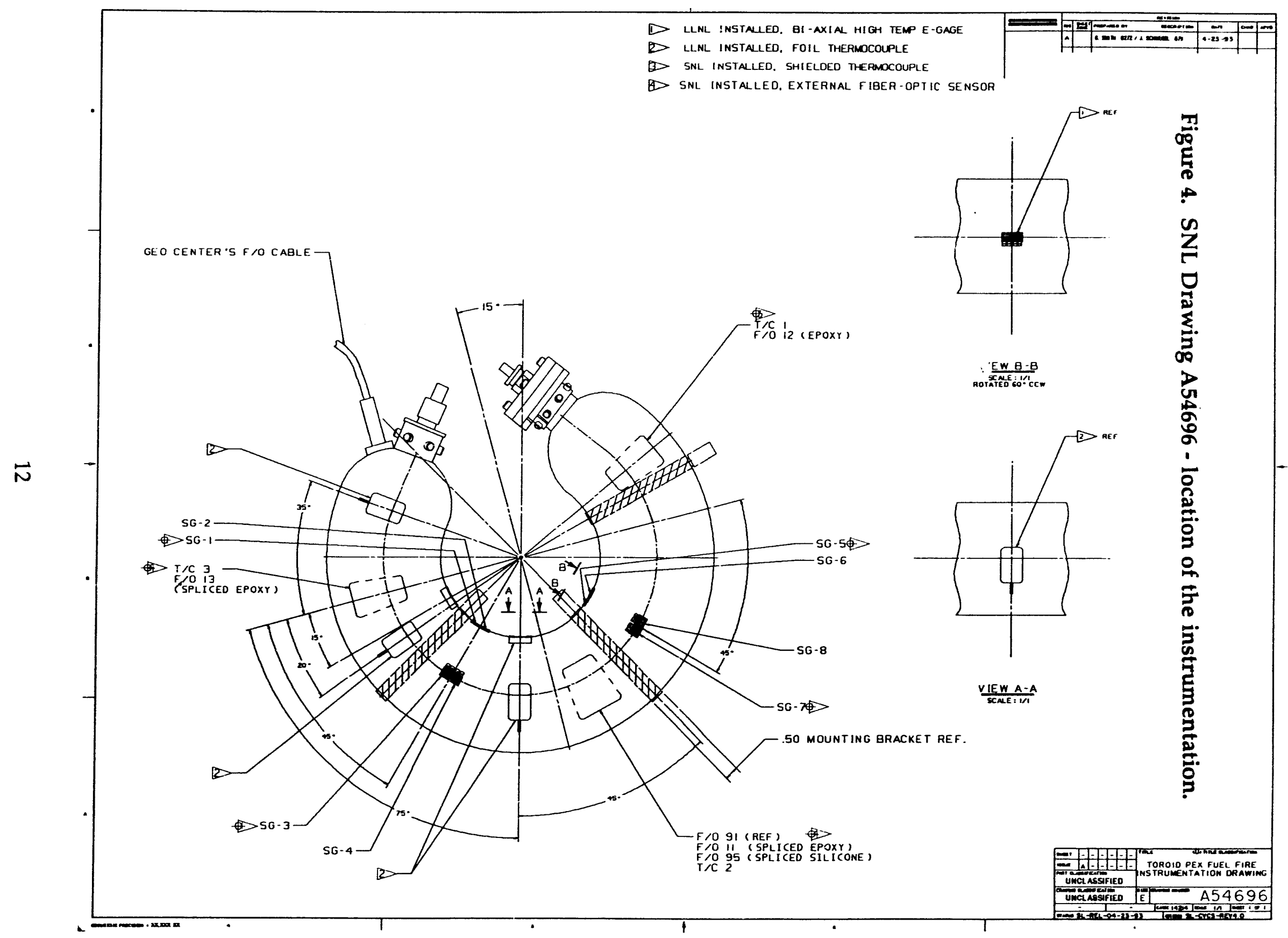




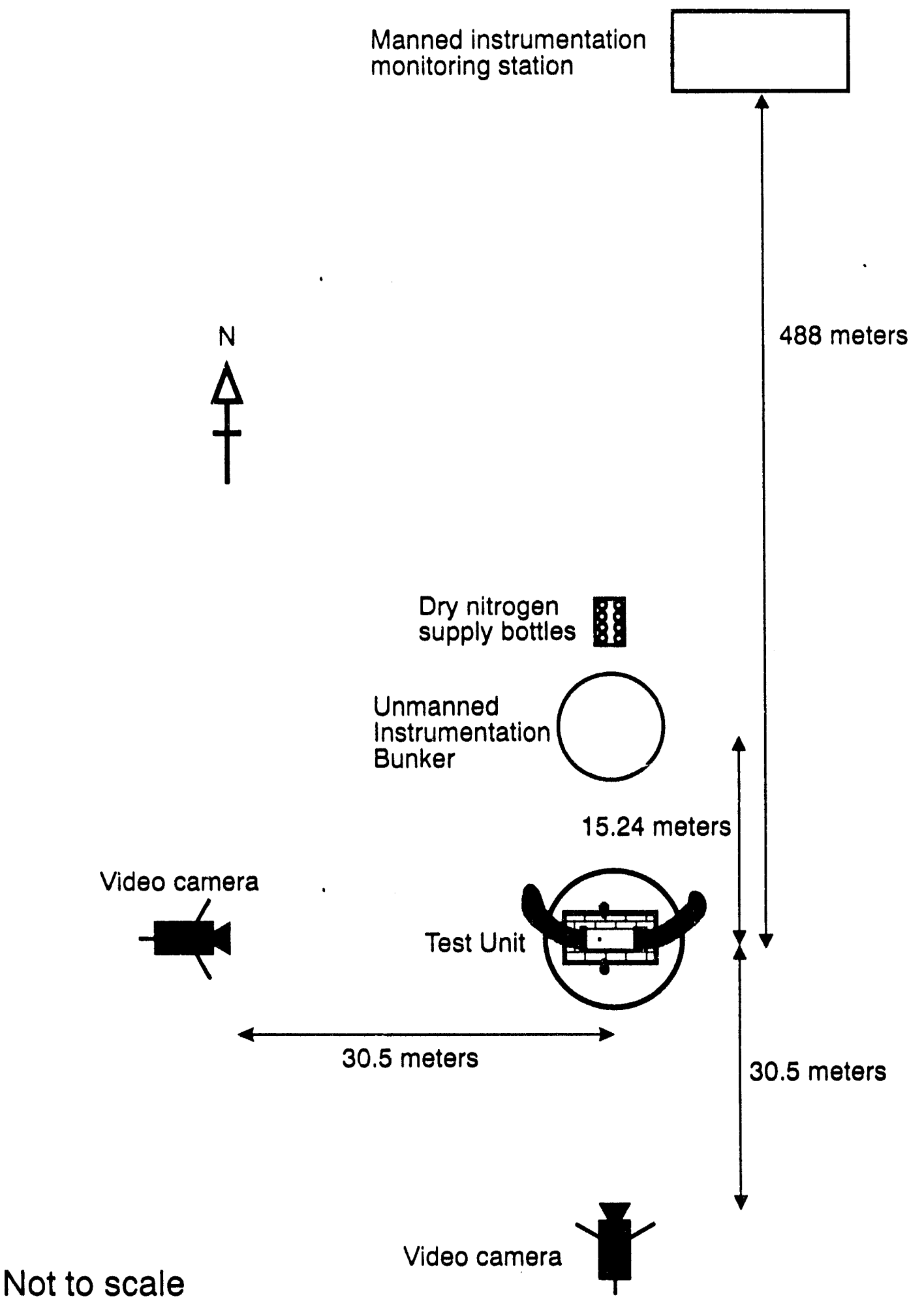

Not to scale

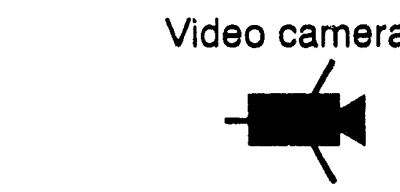

Dry nitrogen

supply bottles

15.24 meters

Figure 5. Diagram of the overall test set-up, as seen from the top view, in the pre-test configuration. 
Figure 6a. Temperatures in flame measured at the three thermocouples mounted on the South Tower - wind from North to South.

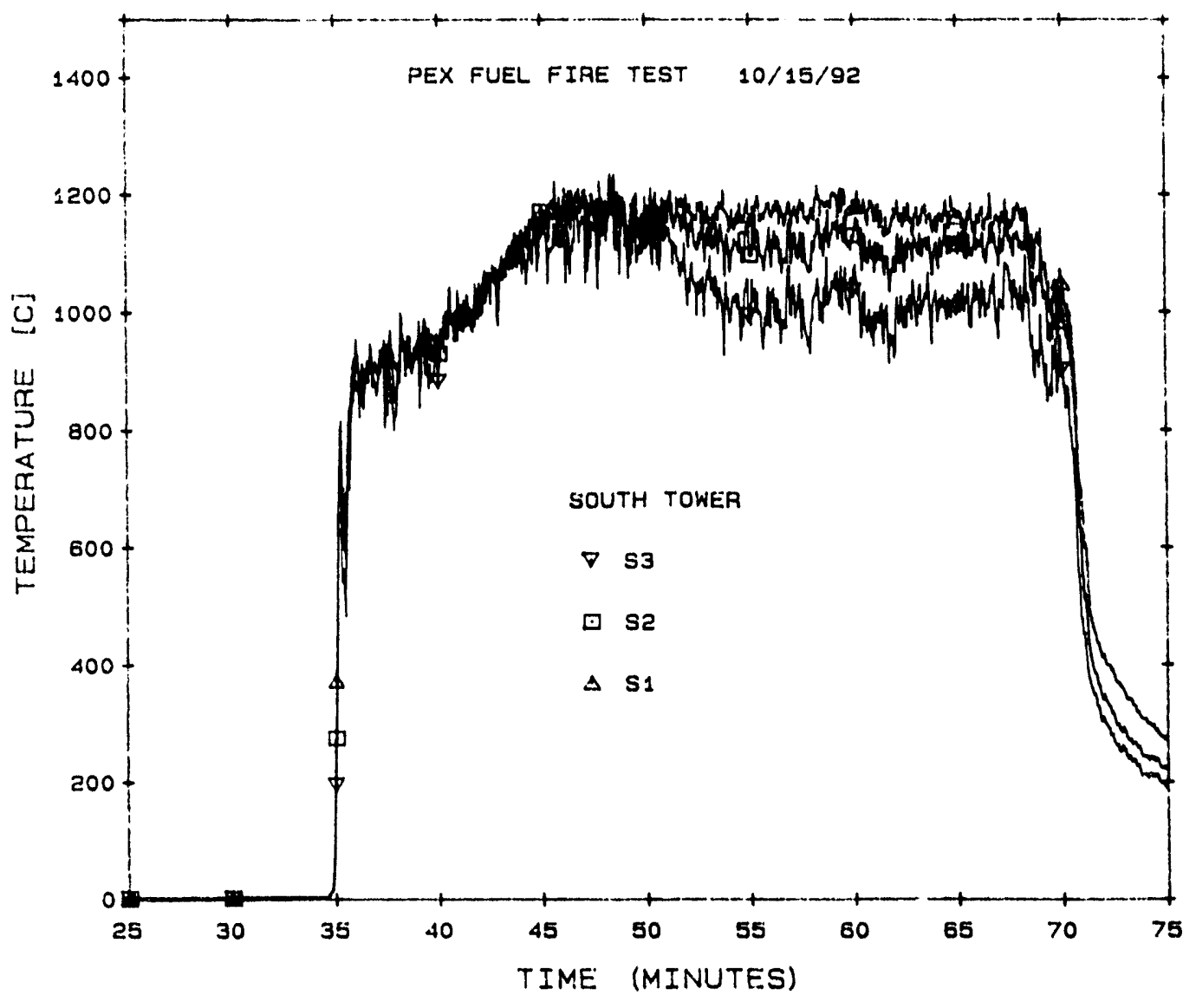

Figure 6b. Temperatures in flame measured at North Tower.

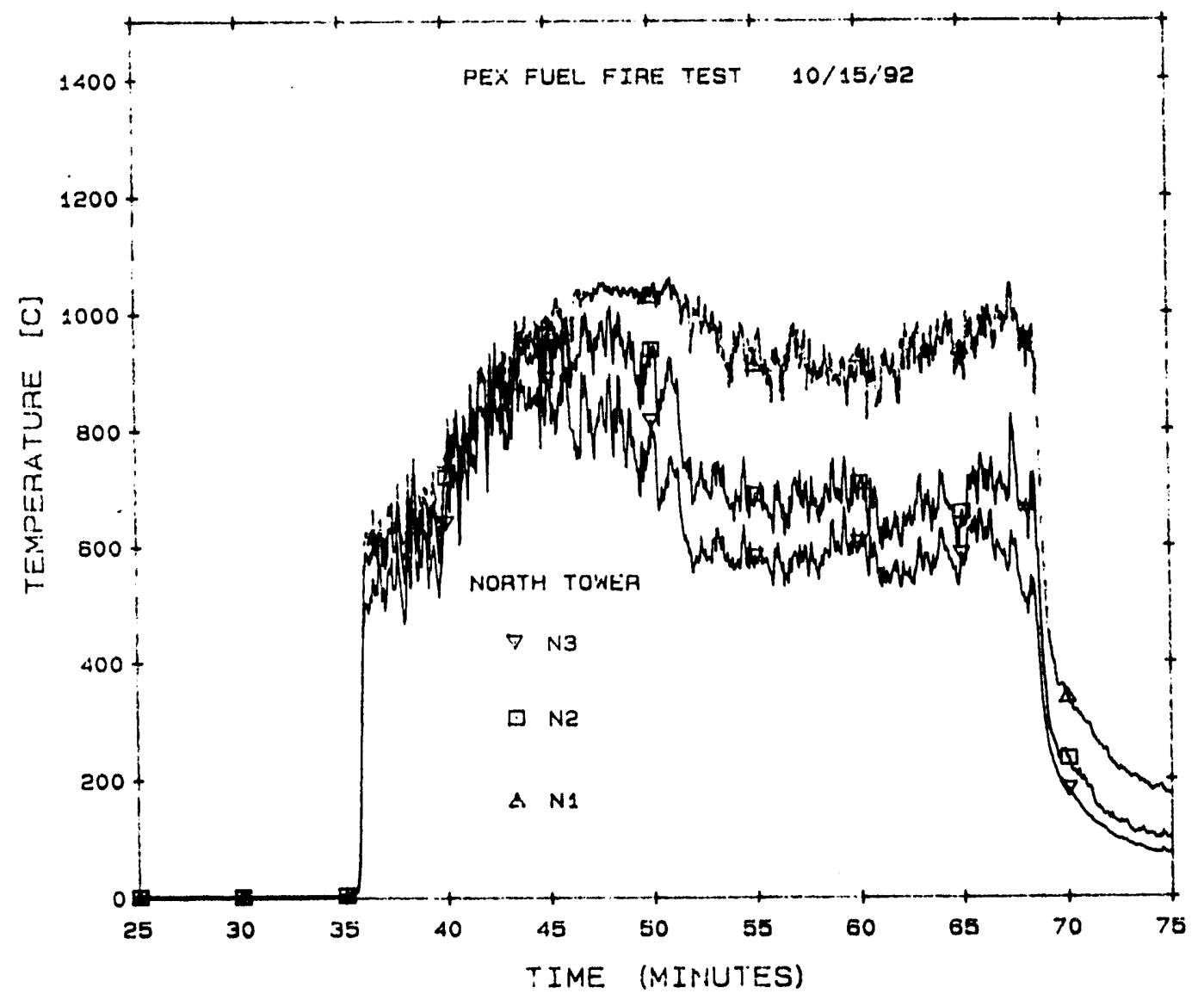




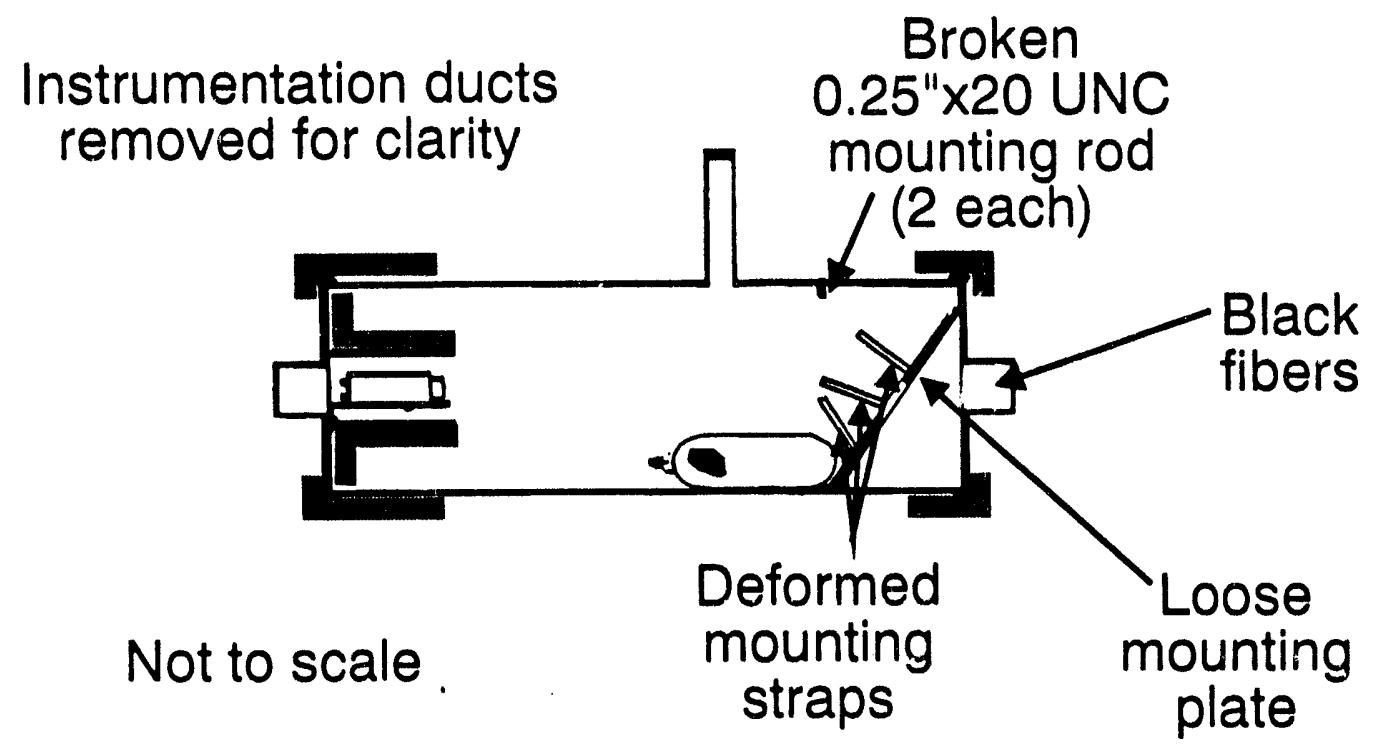

Figure 7. Diagram of the post-test debris configuration. 


\section{Appendix}

MIL-STD-1648A(AS) ${ }^{4}$ defines the following terms, in increasing order of severity:

Burning reaction. The process wherein the ordnance energetic material undergoes combustion. During this reaction, the energetic material enclosure may open up and vent. The item remains in position although it may fall due to structural failure. The burning reaction presents a minimal hazard to fire fighting personnel.

Deflagration reaction. The process wherein the ordnance energetic material undergoes rapid combustion and ruptures its enclosure. The item or major parts thereof may be thrown up to 50 feet by the reaction. No damage due to blast effects or fragmentation. Fire fighting personnel may be endangered or inhibited by expansion of fire and burning material and parts being thrown about.

Explosion. Violent pressure rupture and fragmentation of munition case with resulting air shock. Most of metal case breaks into large pieces which are thrown about with unreacted or burning explosive. Some blast and fragmentation damage to environment. Fire and smol.e damage as in deflagration. Severity of blast could cause minor ground crater, or small depression on flight deck or carrier if munition is large bomb.

Propulsion. The reaction whereby adequate force is produced to impart flight to the test item.

Partial detonation. Only part of total explosive load in munition detonates. Strong air shock, and small as well as large case fragments produced. Small fragments are similar to those in normal munition detonation. Extensive blast and fragmentation damage to environment. Amount of damage and extent of breakup of case into small fragments increases with increasing amount of explosive detonated. Severity of blast could cause large ground crater, or large flight-deck hole on carrier if munition is large bomb; hole size depends on amount of explosive that detonates.

Detonation. Munition performs in design mode. Maximum possible air shock is formed. Essentially all of case is broken into small fragments. Blast and fragment damage is at maximum. Severity of blast causes maximum ground crater or flight-deck hole capable by the munition involved. 
$Y$
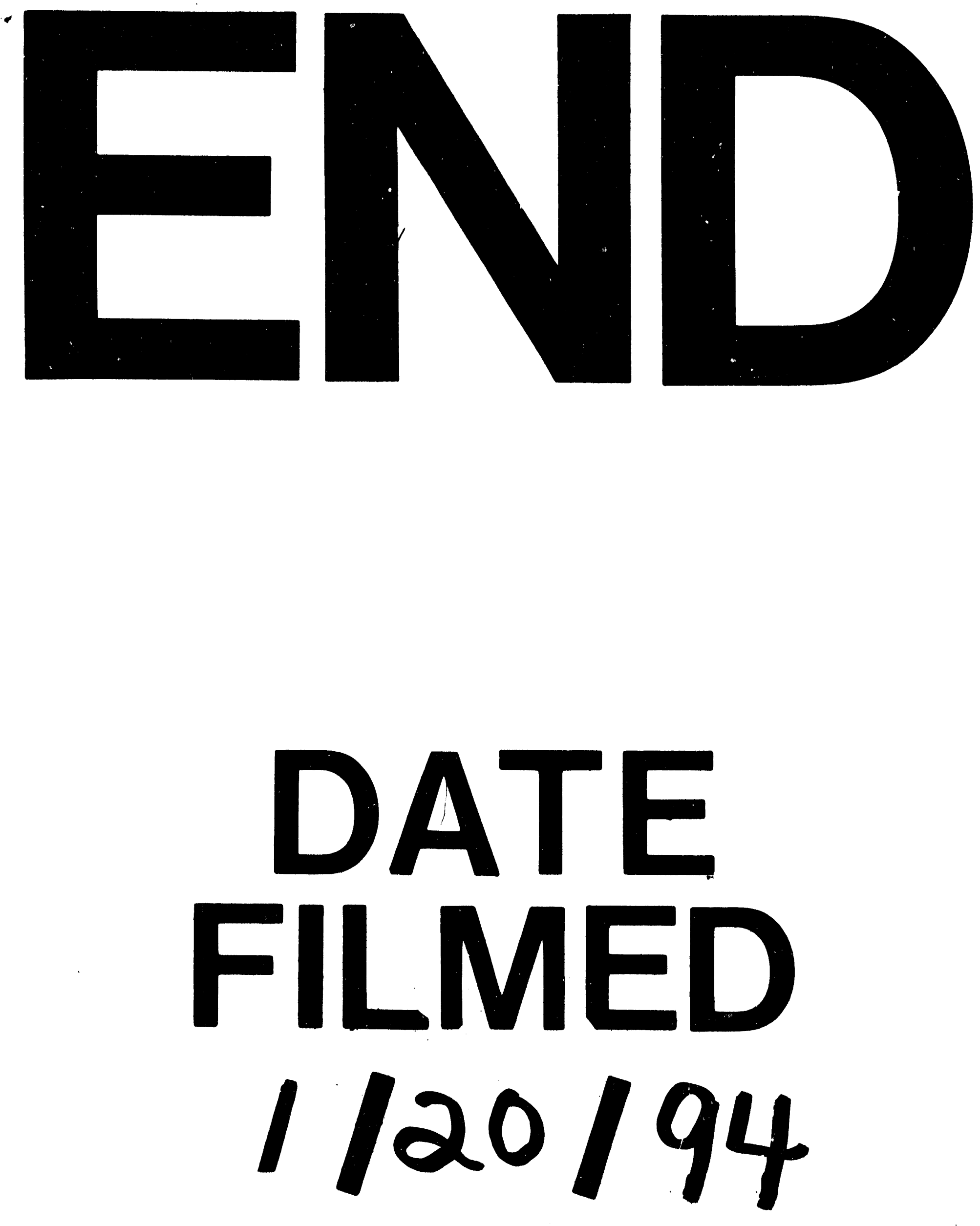
